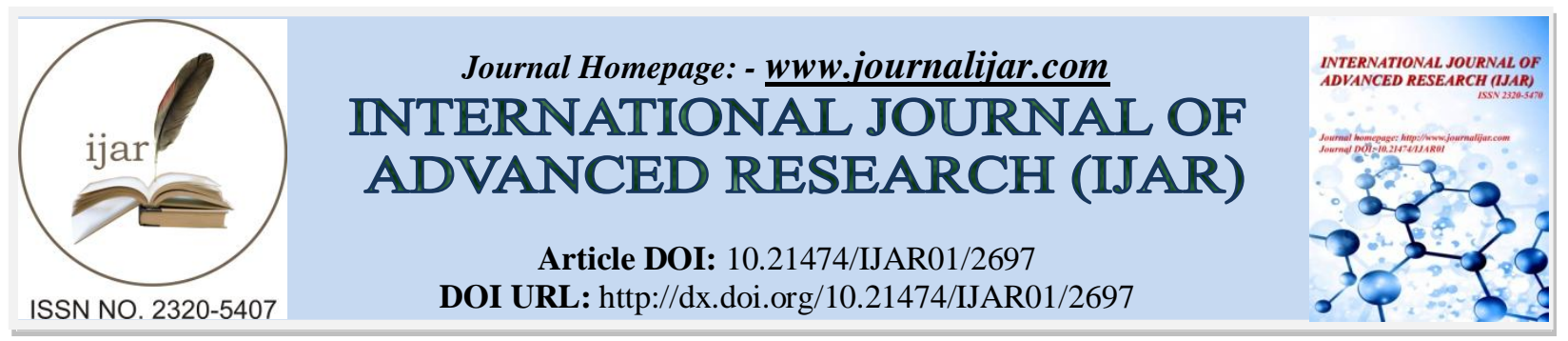

RESEARCH ARTICLE

\title{
CLINICAL FEATURES ,PROGNOSTIC FACTORS \& OUTCOME OF CAPILLARY LEAK SYNDROME IN SNAKE BITE ENVENOMATION.
}

1. Consultant Physician.

\author{
Remi George Thomas ${ }^{1}$ and Jayesh Kumar ${ }^{2}$.
}

2. Professor of Medicine, Government Medical College Calicut.

\section{Manuscript Info}

n........................

Manuscript History

Received: 31 October 2016

Final Accepted: 01 December 2016

Published: December 2016

\section{Abstract}

This paper is about the full sized keyboard that is implemented using the image processing. In this type of keyboard the image of the keyboard is being projected on any plane surface and a pre calibrated camera tracks the movement of the fingers on the image and detects key being pressed. This keyboard uses embedded system and image processing to let the users work on any surface they want with a higher portability option. This technology has many application in various high tech and industrial sectors where the keyboards would be in sterile and low noise environments for example operation theatres.

Copy Right, IJAR, 2016,. All rights reserved.

\section{Introduction:-}

Snake bite is an important medical emergency in tropical countries. Capillary leak syndrome complicating venomous snake bite, characterized externally by parotid swelling,conjunctival chemosis and periorbital edema coupled with hypotension,albuminuria,hypoalbuminemia and haemoconcentration is an under-recognized clinical entity.In recent times, this syndrome has increasingly been reported from pockets in South India particularly North Kerala and Pondicherry in Tamil Nadu.Even among the victims of snake bite, who present early to medical facilities and receive adequate quantities of Snake Antivenom(SAV), the development of capillary leak syndrome is associated with high mortality .Published literature regarding the clinical features and prognostic factors of this dangerous complication is scarce. The role of SAV,steroids and other treatment modalities in the management of capillary leak also need to be outlined clearly by well validated studies exclusively dealing with this complication.

In the present study,we attempted to focus our attention exclusively on patients developing capillary leak following snake bite,to outline the clinical features and progression of this entity,analyse the prognostic factors,assess the mortality predictors and role of individual treatment modalities with regard to outcome.

\section{Methods:-}

This cross sectional observational study was conducted among patients above 12 years of age admitted following snake bite in the Snake Bite Management Unit under the Department of Medicine,Government Medical College ,Kozhikode - a tertiary care hospital in North Kerala.Capillary leak was defined by the presence of bilateral parotid swelling,chemosis of conjunctiva and periorbital edema following snake bite along with documentary evidence of hypotension (Blood pressure $<90 / 60 \mathrm{mmHg}$ or fall of Mean arterial pressure by $30 \mathrm{mmHg}$ ,haemoconcentration(males $>47 \%$; females $>40 \%$ ),albuminuria(protein-creatinine ratio $>1$ in two successive samples),hypoalbuminemia(Serum albumin $<3 \mathrm{gram} / \mathrm{dl}$ ) and sonological evidence of third space fluid collection 
(any 3). Ethical clearance was obtained from Institutional Ethics and Research Committee. The temporal evolution of symptoms and signs from the time of snake bite was gathered by a detailed review of history from the subjects and from the caregiver. Relevant background data,native practices employed,time delays during transport to competent medical facilities, time of Snake Anti Venom(SAV) administration and blood investigations were also collected from appropriate sources for every patient included in the study. The twenty minute Whole Blood Clotting Test (20WBCT) was used to detect haemotoxic envenomation and all patients received 20 vials of SAV. Those subjects who required critical care, interventional procedures like central venous pressure monitoring and dialytic support were admitted to the Intensive Care Units for further management.The time of appearance of parotid swelling,conjunctival chemosis and periorbital edema was noted as the clinical onset of capillary leak.Crystalloids like normal saline,colloids (intravenous 20\% Human Albumin) and fresh frozen plasma(FFP) were used whenever indicated in the course of management. Laboratory investigations, development of complications and mortality were correlated with reference to the time of snake bite and from clinical onset of capillary leak. The role of SAV,steroids ,colloids and fresh frozen plasma in the management of capillary leak following snake bite was observed and outcome analysis was done by relevant statistical tests using SPSS software(IBM SPSS Statistics Version ). The primary outcome studied was mortality.Secondary variables included incidence of complications and predictive factors for survival. p value less than 0.05 was taken as significant.

\section{Results:-}

Twenty seven patients admitted to Snake Bite Management Unit during the 9 months study period satisfied the criteria for capillary leak. Majority (81.5\%) were males. The age distribution of subjects varied from 13 to 65 years. Most cases were reported from semi-urban areas(63\%) predominantly among the working class $(74.1 \%)$.

Capillary leak occurred more during the summer months and among those bitten at night. Snake was reliably identified as Russell's viper in all cases. All patients primarily showed features of haemotoxic envenomation. Additionally neurotoxic features were seen in 3 cases.Rapid systemic envenomation within 3 hours was noted in twenty one out of 27 patients (77.8\%).Twenty five out of 27(92.6\%) reached Government Medical College,Kozhikode within 12 hours after the bite.Snake Anti Venom(SAV) was administered within 6 hours in the majority $(77.8 \%)$ of patients. Twenty vials of SAV was used in all cases.Clotting time remained prolonged inspite of 20 vials of SAV even after 24 hours of the bite in 10 out of 27 cases(37\%). Spontaneous bleeding developed in 18 out of 27 subjects (66.7\%). Hypotension and low central venous pressure was noted in 9 out of 27 cases (33.3\%).Intravenous $20 \%$ Human albumin was used in 10 subjects(37\%).

The most common time of onset of parotid swelling,conjunctival chemosis and periorbital edema was between 12 to 24 hours after the bite as seen in 19 out of 27 cases(70.4\%).Parotid swelling was the earliest among the three. Five patients received methylprednisolone as early as within 12 hours of snake bite after appearance of external features of capillary leak.Total count elevation $>20,000 / \mathrm{dl}(18$ out of $27 ; 66.6 \%)$,thrombocytopenia $<1,00,000 / \mathrm{dl}$ ( 14 out of $27 ; 51.8 \%$ ) and albuminuria $>1$ gram/24 hours $(23$ out of $27 ; 88.9 \%$ ) were observed within 12 hours of bite. A rise in haematocrit was noted in 18 out of 27 cases $(66.6 \%)$.Hypoalbuminemia $<3.5$ gram/dl was a delayed laboratory finding among the capillary leak subjects.It appeared only after 48 hours of the bite in 18 out of 27 (66.6\%).The most common complications of capillary leak syndrome observed were acute kidney injury (100\%), disseminated intravascular coagulation(48\%) and acute respiratory distress syndrome(44\%).

Of the 27 cases, 16 patients died. Mortality was 59.3\%.Although capillary leak cases were more during the summer months, mortality was higher during the rainy season ( 9 out of 10 cases; $p<0.01$ ).Also snake bites during the night associated strongly with mortality(13 out of 18 cases; $\mathrm{p}<0.05)$. The application of tourniquet,presence of additional neurotoxic symptoms or dose and timing of antivenom did not show statistical correlation with mortality.Rapidity of envenomation ,presence of spontaneous bleeding and shock,rapid rise in haematocrit and failure to reverse the coagulopathy even with 20 vials of SAV were the definite predictors of mortality(Table 1). 
Table 1:-

\begin{tabular}{|c|c|c|c|c|}
\hline $\begin{array}{lll}\text { SIGNS } & \text { OF } & \text { ENVENOMATION }\end{array}$ & & OUTCOME & & $\mathrm{p}<0.003$ \\
\hline $\begin{array}{llll}\text { WITHIN } & 3 & \text { HOURS } & \text { VERSUS }\end{array}$ & & SURVIVED & DIED & \\
\hline MORTALITY & $\begin{array}{ll}\text { VENOM } & <3 \\
\text { HOURS } & \end{array}$ & 6 & 16 & 22 \\
\hline & $\begin{array}{ll}\text { VENOM } & >3 \\
\text { HOURS } & \end{array}$ & 5 & 0 & 5 \\
\hline $\begin{array}{lll}\text { PRESENCE } & \text { OF } & \text { SPONTANEOUS }\end{array}$ & & OUTCOME & & $\mathrm{p}<0.001$ \\
\hline BLEEDING VERSUS MORTALITY & & SURVIVED & DIED & \\
\hline & YES & 3 & 15 & 18 \\
\hline & $\mathrm{NO}$ & 8 & 1 & 9 \\
\hline 20 MINCLOTTING $\quad$ TIME & & OUTCOME & & $\mathrm{p}<0.001$ \\
\hline PROLONGATION BEYOND 24 & & SURVIVED & DIED & \\
\hline HOURS & YES & 0 & 10 & 10 \\
\hline & $\mathrm{NO}$ & 11 & 6 & 17 \\
\hline $\begin{array}{l}\text { HAEMATOCRIT RISE WITHIN } 12 \\
\end{array}$ & & OUTCOME & & $\mathrm{p}<0.002$ \\
\hline HOURS VERSUS MORTALITY & & SURVIVED & DIED & \\
\hline & YES & 0 & 9 & 9 \\
\hline & $\mathrm{NO}$ & 11 & 7 & 18 \\
\hline $\begin{array}{llll}\text { PRESENCE } & \text { OF } & \text { SHOCK } & \text { VERSUS }\end{array}$ & & OUTCOME & & $\mathrm{p}<0.02$ \\
\hline MORTALITY & & SURVIVED & DIED & \\
\hline & YES & 1 & 8 & 9 \\
\hline & $\mathrm{NO}$ & 10 & 8 & 18 \\
\hline
\end{tabular}

\section{Discussion:-}

Snake venom, is a mixture of enzymatic and non-enzymatic compounds as well as other nontoxic proteins including carbohydrates and metals. There are over 20 different enzymes including phospholipases A2, B, C, D hydrolases, phosphatases (acid as well as alkaline), proteases, esterases, acetyl cholinesterase, transaminase, hyaluronidase, phosphodiesterase, nucleotidase and ATPase and nucleosidases (DNA and RNA). The non-enzymatic components are loosely categorized as neurotoxins and hemorrhagens. These hemorrhagens are zinc containing metalloproteinases which degrade the compact proteins of basement membrane underlying endothelial cells. They also act on endothelial cells causing lysis or drifting apart of vascular endothelium leading to shift of fluid from intravascular to interstitial space. Two vascular apoptosis inducing proteins VAP1 and VAP2 that damage endothelial cells have been identified. The apoptotic activity of VAP2 is specific for endothelial cells.6 Snake venom has also been found to produce reactive oxygen species in endothelial cells (ROS) which lead to apoptosis. Serine protease - a capillary permeability increasing enzyme (CPI-2), has been isolated from the venom of snakes. The pathophysiologic basis for morbidity and mortality is the disruption of normal cellular functions by these enzymes and toxins. Some enzymes such as hyaluronidase disseminate venom by breaking down tissue barriers. The variation of venom composition from species to species explains the clinical diversity of ophitoxemia. There is also considerable variation in the relative proportions of different venom constituents within a single species throughout its geographical distribution, at different seasons of the year and as a result of aging. The various venom constituents have different modes of action. Ophitoxemia leads to increase in the capillary permeability, which may cause loss of blood and plasma volume into the extravascular space. This accumulation of fluid in the interstitial space is responsible for edema. The decrease in the intravascular volume may be severe enough to compromise circulation and lead on to shock. Snake venom also has direct cytolytic action causing local necrosis and secondary infection, a common cause of death in snakebite patients. Hypotension and shock are common in patients bitten by Vipera species (e.g., V. palaestinae and V. berus), some of the North American rattlesnakes (e.g., C. adamanteus, C. atrox and C. scutulatus), Bothrops and Daboia. They may also occur with Echis carinatus (saw-scaled viper) bite. The central venous pressure is usually low and the pulse rate rapid, suggesting hypovolemia, for which the usual cause is extravasation of fluid into the bitten limb. Patients envenomed by Burmese Russell's vipers show evidence of generally increased vascular permeability. The pathological changes in the capillary by BaH1, a hemorrhage metalloproteinase isolated from bothrops asper was studied in mouse gastrocnemius muscle after intravascular injection of the toxin. At the ultrastructural level the earliest change was decrease in the number of pericyte vesicles, cytoplasmic projections into vascular lumen and detachment of the endothelial cell from the surrounding lamina 
with thinning of the endothelial cell. Capillaries showed gaps in endothelium through which fluid leaks to the interstitial space.

\section{References:-}

1. Chippaux JP. Snakebites: appraisal of the global situation. Bull WHO 1998;76:515-24

2. Assaly R, Olson D, Hammersley J, et al. Initial evidence of endothelial cell apoptosis as a mechanism of systemic capillary leak syndrome. Chest 2001;120:1301-08.

3. Masuda S, Hayashi H, Araki S. Two vascular apoptosis-inducing proteins from snake venom are members of metalloproteases/disintegrin family. European Journal of Biochemistry 1998;253:36-41.

4. Vigneau C, Haymann JP, Khoury N, Sraer JD, Rondeau. An unusual evolution of the systemic capillary leak syndrome. Nephrol Dial Transplant 2002;17:492-4.

5. Narvencar K. Correlation between timing of ASV administration and complications in snake bites. J Assoc Physicians India 2006;54:717-9. 